\title{
Determinants of Attendance at the University Hospital Center-National Odontostomatology Center of Bamako CHU-CNOS
}

Baba Diallo $^{1 *}$, Sow Kadidia ${ }^{1}$ Toure, Ousseynou Diawara ${ }^{1}$, Amady Coulibaly ${ }^{1}$, Abdoul Aziz Traore ${ }^{1}$, Aboubacar S. T. Kane ${ }^{2}$, Bougadary Couloubaly ${ }^{1}$,Oumar Sangho ${ }^{3}$, Mahamadou Diakite ${ }^{3}$ Hamza Keita $^{4}$, Namory Coulibaly ${ }^{4}$, Adama Traore ${ }^{1}$, Seydou Samake ${ }^{1}$, David Diarra ${ }^{1}$, Nenè Ballo ${ }^{1}$, Boubacar Ba ${ }^{1}$, Hamady Traore ${ }^{1}$

\author{
${ }^{1}$ University Hospital Center National Odontostomatology Center of Bamako, Mali \\ ${ }^{2}$ Odontology Department, Infirmary Bamako Hospital, Mali \\ ${ }^{3}$ DERSP DER Public Health, Faculty of Medicine and Odontostomatology FMOS, Mali \\ ${ }^{4}$ National Institute for Training in Health Sciences, Mali
}

DOI: $10.36347 /$ sjds.2021.v08i05.001

| Received: 19.04.2021 | Accepted: 02.06.2021 | Published: 06.06.2021

*Corresponding author: Dr. Baba Diallo

\section{Abstract}

Introduction: According to the World Health Organization (WHO), the determinants of health facility attendance are "personal, social, economic and environmental factors that determine the state of health of individuals or populations". The objective of this study was to study the determinants of attendance at CHU-CNOS. Methodology: The study took place within the CHU-CNOS. This was an analytical cross-sectional study that took place over a period of 6 months (July to December 2020). Patients who received treatment at CHU-CNOS constituted the study population. All patients who received treatment at the CHU-CNOS and who agreed to participate in the study were included in this study.The sample size was $n=420$ patients. The questionnaire survey and the questionnaire were respectively the technique and the data collection tool. The questionnaire was administered face to face to patients to collect data. Data entry and analysis were performed on EPI INFO 2000 version 7 and SPSS software version IBM SPSS Statistics 2, respectively. Results: More than half of those surveyed was $52.1 \%$ female. The sex ration was 0.92 . Bride and groom represented $66 \%$ of the study population. Of the people surveyed, $35.7 \%$ were not in school. Civil servants made up $21.9 \%$ of respondents. The majority of respondents $(90.2 \%)$ found that the costs of care at the CHU-CNOS were affordable. The average cost of care was 3,965 FCFA with a standard deviation of 1,245 FCFA (3,965 \pm 1245 FCFA). The $30.4 \%$ of those surveyed said that the costs of prescribed drugs were high. The average cost of prescribed drugs was $6,635 \pm 1,400$ FCFA. The satisfaction rate of the people surveyed was $80.7 \%$.. Among the unsatisfied patients surveyed, $63 \%$ had the waiting time in front of the office as a reason for dissatisfaction and $18.5 \%$ felt that the reception was poor.There was a statistically significant relationship to satisfaction with the following variables: level of listening to the patient by the practitioner $(\mathrm{p}<0.001)$ and office hygiene $(\mathrm{p}<0.001)$. Discussion: The satisfaction rate of the people surveyed was $80.7 \%$ and $94.8 \%$ of the people surveyed said they were ready to refer other patients to the CHU - CNOS. These results differ from those obtained by M. Diouf et al. in Senegal in 2010. They found that $21.4 \%$ of the study population expressed that they had been listened to enough $35 \%$ of patients expressed a willingness to recommend this dental care structure.

Keywords: Determinants, attendance, CHU-CNOS, Bamako, Mali.

Copyright $\odot 2021$ The Author(s): This is an open-access article distributed under the terms of the Creative Commons Attribution 4.0 International License (CC BY-NC 4.0) which permits unrestricted use, distribution, and reproduction in any medium for non-commercial use provided the original author and source are credited.

\section{INTRODUCTION}

According to the World Health Organization (WHO), the determinants of health facility attendance are "personal, social, economic and environmental factors that determine the state of health of individuals or populations."

These are factors that can directly or indirectly influence the health status of populations. They act in isolation or in association. The complex interactions between these factors determine the health of individuals and populations. It is a series of factors that have actions that can be positive or negative on the health or well-being of an individual or a population [1].

In 2010 Samba M. et al. in Côte d'Ivoire found that the lack of financial means was the first obstacle to accessibility to oral care during a study on the therapeutic route in odonto-stomatology [2]. 
In a study on the determinants of access to health services in Grand-Bassam in Côte d'Ivoire in 2018, Wilfried M.G. et al. found that the following determinants influence access to health services: perception of distance, income of the head of household, perception of cost, household size and level of education and [3].

\section{METHODOLOGY}

The study took place within the CHU-CNOS. This was an analytical cross-sectional study that took place over a period of 6 months (July to December 2020). It took place at CHU_CNOS. Patients who received treatment at CHU-CNOS constituted the study population. Was included in this study any patient who benefited from treatment at the CHU-CNOS and who agreed to sign the informed consent form. Any patient who did not agree to sign the informed consent form and new patients were not included in this study. The sample size was $n=420$ patients.
The questionnaire survey was the collection technique. The questionnaire was the collection tool. It was administered face to face to patients to collect data.

Socio-demographic characteristics, care costs, personnel / work environment factors, user satisfaction and geographic accessibility were the main groups of variables.

Data entry and analysis were performed on EPI INFO 2000 version 7 and SPSS software IBM SPSS Statistics 2 version respectively. Arrangements have been made to maintain the integrity of respondents. The protocol was submitted for approval to the Ethics Committee of the Faculty of Medicine and Odonto-Stomuatology (FMOS).

\section{RESULTS}

- Socio - demographic characteristics of respondents

- Sex



Fig-1: Distribution of respondents by gender

More than half of the people surveyed were $52.1 \%$ female. The sex ratio was 0.92 . The average age of the people surveyed was $31 \pm 9$ years.

\section{Marital status}

Table-I: Distribution of respondents by marital status

\begin{tabular}{|l|c|l|}
\hline Marital status & Effectifs & Percentage (\%) \\
\hline Single & 129 & 30,7 \\
\hline Married & 277 & 66,0 \\
\hline Divorced & 5 & 1,2 \\
\hline Widower & 9 & 2,1 \\
\hline Total & $\mathbf{4 2 0}$ & $\mathbf{1 0 0 , 0}$ \\
\hline
\end{tabular}

Bride and groom represented $66 \%$ of the study population.

\section{Education level}

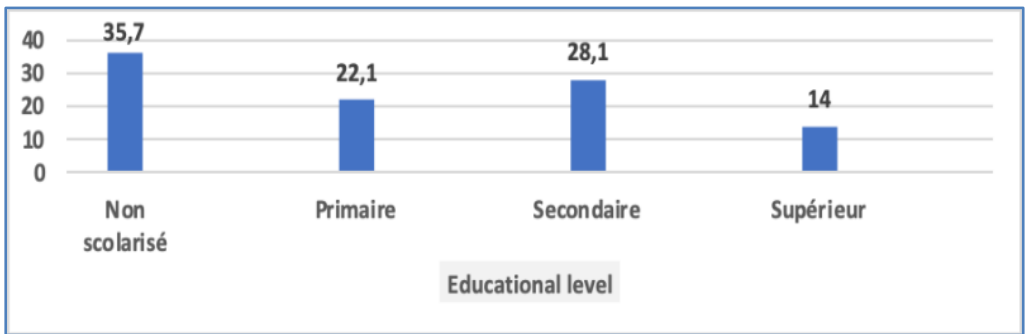

Fig-2: Distribution of the study population according to the level of education of the people surveyed, $35.7 \%$ were not in school. 
Determinants related to the costs of the services received

Reminder: The costs of consultations at the CHU-CNOS are set at 1,500 FCFA (for the uninsured) and 450 FCFA for holders of compulsory health insurance (AMO). About $90 \%$ of those surveyed said the consultation fees were affordable. The majority of respondents $(90.2 \%)$ found that the costs of care at the CHU-CNOS were affordable. The average cost of care was 3,965 FCFA with a standard deviation of 1,245 FCFA $(3,965 \pm 1245$ FCFA). The average cost of prescribed drugs was $6,635 \pm 1,400$ FCFA (high cost for $70 \%$ of respondents).

\section{Possession of health insurance}

Almost three-quarters of respondents $(73.1 \%)$ did not have health insurance. Monthly income.

Among the respondents with an income $60.2 \%$ had a monthly income less than 100,000 FCFA. Determinants related to staff attitudes and the work environment.

\section{Home}

Table-II: Distribution of respondents according to their opinion on the reception

\begin{tabular}{|l|l|l|}
\hline Respondents' opinions on the reception & Effectifs & Percentage (\%) \\
\hline Well & 281 & 66,9 \\
\hline Acceptable & 124 & 29,5 \\
\hline Bad & $\mathbf{1 5}$ & $\mathbf{3 , 6}$ \\
\hline Total & $\mathbf{4 2 0}$ & $\mathbf{1 0 0 , 0}$ \\
\hline
\end{tabular}

Of all those surveyed, $3.6 \%$ said that the reception was poor. The majority of respondents (93.1\%) found that the practitioners listened to the) the dental offices in the center were comfortable $(93.3 \%$.

\section{User satisfaction}

The satisfaction rate of the people surveyed was $80.7 \%$. Almost all respondents $(99.5 \%)$ confirmed having received the care they requested and $90.7 \%$ of respondents claimed to have known the CHU - CNOS through third parties.

\section{Reasons for dissatisfaction}

Table-III: Breakdown of dissatisfied respondents according to the reasons

\begin{tabular}{|l|l|l|}
\hline Reasons for dissatisfaction & Effectifs & Percentage (\%) \\
\hline Bad reception & 15 & 18,5 \\
\hline Long registration waiting time & 13 & 16,0 \\
\hline Waiting time for treatment in front of the office & 51 & $\mathbf{6 3}$ \\
\hline Inability to whiten teeth & 2 & 2,5 \\
\hline Total & $\mathbf{8 1}$ & $\mathbf{1 0 0 , 0}$ \\
\hline
\end{tabular}

Among the unsatisfied patients surveyed, 63\% had the waiting time in front of the office as a reason for dissatisfaction and $18.5 \%$ felt that the reception was poor.
- Waiting time for treatment in front of the office was considered too long (90 to 120 minutes)

- Time taken for registrations varied from 60 to 90 minutes.

\section{Motivation for services at CHU - CNOS}

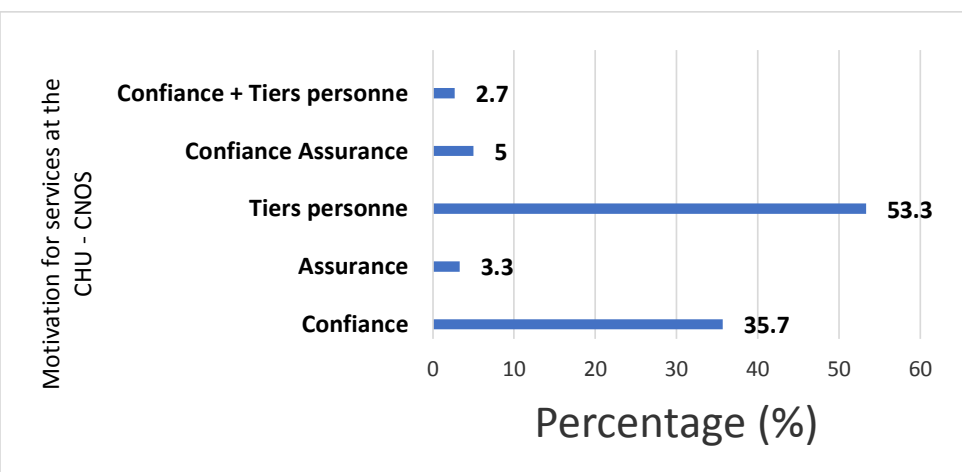

Fig-4: Distribution of respondents according to their motivation for the services at CHU-CNOS 
More than half of the respondents $(53.3 \%)$ were motivated by third parties for the services at the CHU-CNOS.

\section{Reason for consultation}

Table-IV: Distribution of respondents by reason for consultation

\begin{tabular}{|l|l|l|}
\hline Reason for consultation & Effectifs & Percentage (\%) \\
\hline Pain & $\mathbf{2 4 8}$ & $\mathbf{5 9 , 0}$ \\
\hline Swelling & 73 & 17,4 \\
\hline Aesthetic & 67 & 16,0 \\
\hline Pain + Swelling & 28 & 6,7 \\
\hline Pain + Aesthetics & 4 & 1,0 \\
\hline Total & $\mathbf{4 2 0}$ & $\mathbf{1 0 0 , 0}$ \\
\hline
\end{tabular}

Pain was the most frequent reason for consultation with $59 \%$ of cases.

\section{Geographic accessibility determinants}

About $3 / 4$ of respondents $(77.6 \%)$ considered that access to the CHU - CNOS is easy. The average distance between the residence and the CHU-CNOS was estimated at $11.2 \pm 1.6 \mathrm{~km}$.

\section{Analytical results}

Table-V: Relationship between gender and user satisfaction

\begin{tabular}{|l|l|l|l|}
\hline \multirow{2}{*}{ Sex } & \multicolumn{2}{|l|}{ Satisfaction } & \multirow{2}{*}{ Total } \\
\cline { 2 - 3 } & Yes & No & \\
\hline Female & 176 & 43 & 219 \\
\hline Male & 163 & 38 & 201 \\
\hline Total & $\mathbf{3 3 9}$ & $\mathbf{8 1}$ & $\mathbf{4 2 0}$ \\
\hline
\end{tabular}

We did not find a statistically significant link between gender and satisfaction

Table-VI: Distribution of usé satisfaction according to the level of education

\begin{tabular}{|l|l|l|l|}
\hline \multirow{2}{*}{ Educational level } & \multicolumn{2}{|l|}{ Satisfaction } & \multirow{2}{*}{ Total } \\
\cline { 2 - 3 } & Yes & No & \\
\hline Unschooled & 114 & 36 & 150 \\
\hline Primary & 85 & 8 & 93 \\
\hline Secondary & 95 & 23 & 118 \\
\hline Superior & 45 & 14 & 59 \\
\hline Total & $\mathbf{3 3 9}$ & $\mathbf{8 1}$ & $\mathbf{4 2 0}$ \\
\hline \multicolumn{2}{|l}{$\mathrm{X}^{\mathbf{2}}: 9,7$ ddl: 3 p: 0,02} \\
\end{tabular}

There is a statistically significant link between the level of education and usé satisfaction at CHUCNOS.

Table-VII: Distribution of user satisfaction according to "listening to the patient by the practitioner"

\begin{tabular}{|l|l|l|l|}
\hline \multirow{2}{*}{ Listening to the patient / practitioner } & \multicolumn{2}{|l|}{ Satisfaction } & \multirow{2}{*}{ Total } \\
\cline { 2 - 3 } & Yes & No & \\
\hline Oui & 325 & 66 & 391 \\
\hline Non & 14 & 15 & 29 \\
\hline Total & $\mathbf{3 3 9}$ & $\mathbf{8 1}$ & $\mathbf{4 2 0}$ \\
\hline
\end{tabular}

$$
\mathrm{X}^{2}: 21,08 \text { ddl }: 1 \mathrm{p}: 0,001
$$

There is a statistically significant link between practitioner listening to the patient and satisfaction.

Table-VIII: Relationship between the assessment of practice hygiene and satisfaction

\begin{tabular}{|l|l|l|l|}
\hline \multirow{2}{*}{ Practice hygiene } & \multicolumn{2}{|l|}{ Satisfaction } & \multirow{2}{*}{ Total } \\
\cline { 2 - 3 } & Yes & No & \\
\hline Well & 281 & 48 & 329 \\
\hline Acceptable & 55 & 30 & 85 \\
\hline Bad & 3 & 3 & 6 \\
\hline Total & $\mathbf{3 3 9}$ & $\mathbf{8 1}$ & $\mathbf{4 2 0}$ \\
\hline \multicolumn{3}{|c}{$\mathrm{X}^{\mathbf{2}}: 22,01 \mathrm{ddl}: 2 \mathrm{p}: 0,001$}
\end{tabular}

There is a statistically significant relationship between practice hygiene and satisfaction.

\section{COMMENTS AND DISCUSSION}

- Socio - demographic characteristics of respondents

By Gender

In this study, more than half of the people surveyed were female, i.e. $52.1 \%$ of cases with a sex ratio of 0.92 . this result is comparable to that obtained by B. Diallo et al. (53.3\%). This female predominance could be explained by the fact that women are much more concerned about their oral health than men [4].

By level of education Among the people surveyed, $35.7 \%$ have not been educated. This result is comparable to that of Kabore et al. who reported that illiterate patients were $20 \%$ in their study [5]. This result could be explained by the fact that the $\mathrm{CHU}$ CNOS is a public hospital center. 


\section{According to the profession}

Civil servants made up $21.9 \%$ of respondents. This result is superior to that of Kabore et al. who reported that $9.7 \%$ of patients in their study were employees [5]. This difference could be explained by the fact that CHUCNOS is a third point of reference in Mali.

\section{Determinants related to the costs of the services received}

The costs of consultations at the CHU-CNOS are set at 1,500 FCFA (for the uninsured) and 450 FCFA for holders of AMO. The majority of respondents $(90.2 \%)$ found that the costs of care at the CHU-CNOS were affordable. The average cost of care was 3,965 FCFA with a standard deviation of 1,245 FCFA (3,965 \pm 1245 FCFA). In Mexico, Hernades J.F. et al. in 2007 found that poverty limits the use of dental care by poor people [6]. The CHU-CNOS is a public center benefiting from state subsidies. The costs of oral health care are cheaper compared to those of the private sector. According to the study by Sangaré et al. the average price for the care of an oral disease was $2725 \mathrm{~F}$ $\mathrm{Cfa}(4.15 €)$ in Ivorian public health structures [7]. This difference could be explained by state support for CHUCNOS.

\section{Drug costs}

The $70 \%$ of those surveyed said that the costs of prescribed drugs were expensive. The average cost of prescribed drugs was 6,635 FCFA. The drugs available at the center are INNs so the prices are generally within the reach of low and middle income patients. The low prescription of DCI drugs in the facility contributes to the high cost of prescription fees.

\section{Insurance}

Almost three-quarters of the $73.1 \%$ respondents did not have health insurance. Compulsory health insurance (AMO) accounted for $93.7 \%$ of health insurance holders. As for the share of the AMO, this could be explained by its compulsory nature, therefore all civil servants and even contractual employees are members. In Morocco in 2016 Chala S. et al carried out a study on the associates to the use of dental care in a population of Moroccan adolescents. They found a statistically significant association between having medical insurance and the use of dental care [8].

\section{Monthly income}

Among the respondents with a monthly income, $60.2 \%$ had an income below 100,000 FCFA. We did not find a significant association between respondent income and satisfaction; the cost of care was affordable for about $90 \%$ of respondents. According to the study by Kabore et al. the majority of patients $(74.2 \%)$ did not have an income related to their professional activities $(\mathrm{p}=0.0001)$. Among those who had an income, $60.7 \%$ felt that this income was not sufficient to cover the costs of care [5].
Determinants related to staff attitudes and the work environment

\section{User satisfaction}

The satisfaction rate of the people surveyed was $80.7 \%$. The majority $(94.8 \%)$ of those surveyed said they were ready to refer other patients to the CHU - CNOS. These results differ from those obtained by M. Diouf et al. in Senegal in 2010 during a study on patient satisfaction in the dentistry department. They found that $21.4 \%$ of the study population said they had been listened to enough and $53.2 \%$ had received information about their health problem. In this dentistry department, only $35 \%$ of patients expressed a willingness to recommend this dental care structure [9].

The majority of respondents $(93.1 \%)$ found that the practitioners listened to the patients and $78.3 \%$ said that the hygiene in the dental offices of the CHUCNOS was good. These results corroborate with those obtained by A. Sangaré et al. in Ivory Coast in 2009. According to their results, adults claimed to have had recourse to a dental surgeon because of their confidence and the cleanliness of the dental offices [7].

\section{Reason for consultation}

Pain was the most frequent reason for consultation with 59\%. This result is almost similar to that obtained by M. Gunepin et al. They found in 2015 that dental caries was the first reason for emergency dental consultation $(51.6 \%)$ during a study on "Reasons for emergency consultation at the dental office of the medical-surgical group of Gao: what lessons draw ?". The majority of dental emergencies $(61.3 \%)$ are linked to pre-existing pathologies before the screening and / or to risky behaviors from an odontological point of view (poor food and oral hygiene) [10]. D. Berthe et al. in a similar study at Kayes Hospital in 2018 found that pain represented $78.22 \%$ of the reasons for consultation [11].

\section{Reasons for dissatisfaction}

Of all the people surveyed, $3.6 \%$ said that the reception was poor at the entry office of the CHUCNOS.

Among the unsatisfied patients surveyed, 63\% had the waiting time in front of the office as a reason for dissatisfaction

- Waiting time for treatment in front of the office was considered too long. The average was 90 to 120 minutes and often more. This is explained by the delay in serving practitioners and the noncompliance with the order of arrival of practitioners in relation to the order of patient care by some practitioners.

- Time taken for registrations is 60 to 90 minutes. The establishment of the sorting office would allow this problem to be partially solved.

- Geographic accessibility determinants 
- Opinion on the distance between the residence and the CHU-CNOS distance

More than half of respondents, or $54.8 \%$, said that the distance between their residences and the location of the CHU - CNOS is long. A large part of the sample, ie $80 \%$, found the CHU-CNOS to be in a good location.

\section{Access to CHU - CNOS}

About $3 / 4$ of respondents $(77.6 \%)$ considered that access to the CHU - CNOS is easy. This could be explained by the fact that it is located in the city center and thanks to some public transport it can be reached easily.

\section{CONCLUSION}

The long wait in front of the office before being taken care of was mentioned several times by users as a reason for dissatisfaction. The reorganization or better scheduling of appointments by agents would significantly contribute to improving attendance at CHU-CNOS., Agents.

\section{REFERENCES}

1. Organisation mondiale de la Santé, Oral health Genève 2014. [consulté le 2 juin 2019] Disponible sur : http://www.who.int/ topics/oral_health/en.

2. Samba, M., Guinan, J.C. (2004). Itinéraire thérapeutique en Odonto-stomatologie à Abidjan, Odonto-stomatologie tropic, 1(107); 37-40

3. Wilfried, M.J., AlokoN'Guessan, J. (2018). et coll, Les déterminants de l'accès aux services de santé à Grand-Bassam, European Scientific J, 14(6)

4. Diallo, B. (2018). Facteurs influençant le recours des populations aux soins bucco-dentaires des populations des districts sanitaires de Bla et de Niono dans la région de Ségou au Mali, Thèse de
Doctorat: Santé Publique: Institut Supérieur de Formation et de Recherche Appliquée- USJPB.

5. Kaboré, W., Niang, S., Seck, A., Millogo, M., Fall, M., Faye, B. (2017). Facteurs Déterminant Le Retard De Consultation Des Patients Affectés Par La Carie Dentaire À Ouagadougou : Enquête au Centre Municipal de santé bucco-Dentaire. Rev. Iv. Odonto-Stomatol, 19(2), 35-45

6. Hernades, J.F., Acosta-Gio, A.E. (2007). The effect of poverty on access to oral health care. Journal of American Dental Association, 138(11); 1443-1445

7. Sangare, A., Samba, M., Guinan, J.C. (2010). Les déterminants socio-démographiques du recours aux soins bucco-dentaiores traditionnels en Côte d'Ivoire Cahier de Santé Publique, 9(1); 29-38

8. Chala, I.S., Silorh, K., Abouqal, R., Abdallaoui, F. (2016). Facteurs associés au recours aux soins dentaires dans une population d'adolescents Revue de Stomatologie, de CMF et de chirurgie Orale; 117(6); 367-371

9. Diouf, M. Cissé, M., Lo, D, C.M.M. (2010). et coll Evaluation de la satisfaction des patients admis en service d'Odontologie à Dakar Pratiques et Organisation des Soins, 41 (3); 225-230

10. Gunepina, M., Benmansourb, A., Derachec, F., Marescad, S., Blatteaua, É.J., Rissoa, J.J. (2015). Motifs de consultation en urgence au cabinet dentaire du groupement médico-chirurgical de Gao: quelles leçons en tirer? Médecine et armées, 43, 4 ; 345-351

11. Berthé, D., Niaré, L., Sangaré, M., Bamba, S., Traoré, A.A., Kané Aboubacar, S.T. (2018). Motifs de consultation des patients dans le Service d'Odontostomatologie de l'Hopital de Kayes en 2018, Mali. Mali Sante Publique, Juin 2020 Tome $\mathrm{X} \mathrm{N} \mathrm{N}^{\circ} 01$. 